\title{
AN INTERPROFESSIONAL APPROACH TO A DISTANCE LEARNING DILEMMA
}

\author{
Christine Colella ${ }^{1}$, Matthew Rota ${ }^{2}$, and Theresa Beery ${ }^{3}$
}

Keywords: distance education, inter-professional collaboration, storyboarding, nursing, advanced practice education

\section{Framework}

Teaching is not an activity that is done in isolation. It takes colleagues with diverse talents and skills to create and build effective learning tools that improve student learning outcomes. Content, pedagogy, and technical expertise are required when new learning technologies are developed.

Learning in a practice discipline, such as advanced practice nursing, can be particularly challenging. Students must assess, diagnose, and provide care for diverse populations. Their ability to be proficient at these skills could make a difference in whether a patient lives or dies. This is a high stakes profession and the education preparing practitioners is high stakes education.

Teaching nurses to become nurse practitioners is difficult under any circumstances, but when the student is part of a distance learning program the opportunity to role model professional behaviors can be elusive. The American Association of Colleges of Nursing reports that there are currently 65 distance learning nurse practitioner programs with 31 offering their programs entirely online. Almost $22 \%$ of all post-masters Nurse Practitioner programs offer distance education (AACN, 2014).

A differential diagnosis course that was previously taught in an on-campus setting needed to be restructured for students at a distance. The class, which teaches the art and science of differential diagnosis, is foundational in the nurse practitioner program. Learning the method of differential diagnosis assists experienced registered (baccalaureate) nurses in upgrading their critical thinking, information gathering, and decision-making skills to those of an advanced practitioner.

On-campus students have the opportunity to conduct a patient interview with a standardized patient (SP), an actor trained to portray a patient with a uniform set of symptoms and history. Students gather a history, perform a physical assessment, review diagnostic data, and reach a conclusion about what is going on with the patient. They determine a differential diagnosis list with a rationale based on the information gathered. While the use of standardized patients for practice of clinical examinations is common in medical schools, this experience is provided less often to nurse practitioner students. It was highly valued by our on-campus students, as reported in course evaluations.

\footnotetext{
${ }^{1}$ Associate Professor of Clinical Nursing, College of Nursing, University of Cincinnati, 3110 Vine Street, Academic Health Center, Cincinnati, $\mathrm{OH} 45221-0038$.

${ }^{2}$ Instructional Designer, College of Nursing, University of Cincinnati, 3110 Vine Street, Academic Health Center, Cincinnati, OH 45221-0038.

${ }^{3}$ Professor of Nursing, College of Nursing, University of Cincinnati, 3110 Vine Street, Academic Health Center, Cincinnati, OH 45221-0038.
} 
Our problem was determining how we could replicate this experience for our distance learning students who would not be able to personally interact with standardized patients. How could we communicate and role model the subtleties of a patient interview and physical assessment? We wondered if creative use of instructional technology could solve these problems.

The formation of an interprofessional team was required to effectively address our concerns. The team was composed of the course faculty, an instructional designer, and an information technology expert. Using the TPACK Model (Figure 1), team members worked together to create, develop, implement, and evaluate an interactive case study (ICS). The TPACK Model describes the positive interactions that flow from a synergistic relationship among the faculty, instructional design expert, and the instructional technology expert (Koehler \& Mishra, 2008). Utilizing this model gave the team a visual that demonstrated the value and inter-dependency of each member.

The plan was to create an ICS accessible to distance learning students that mirrored the experience of interacting with a SP. This ICS is unique because it is done in the first person to role model the process and art of differential diagnosis while allowing the student to feel present at the encounter.

Figure 1

\section{TPACK model}

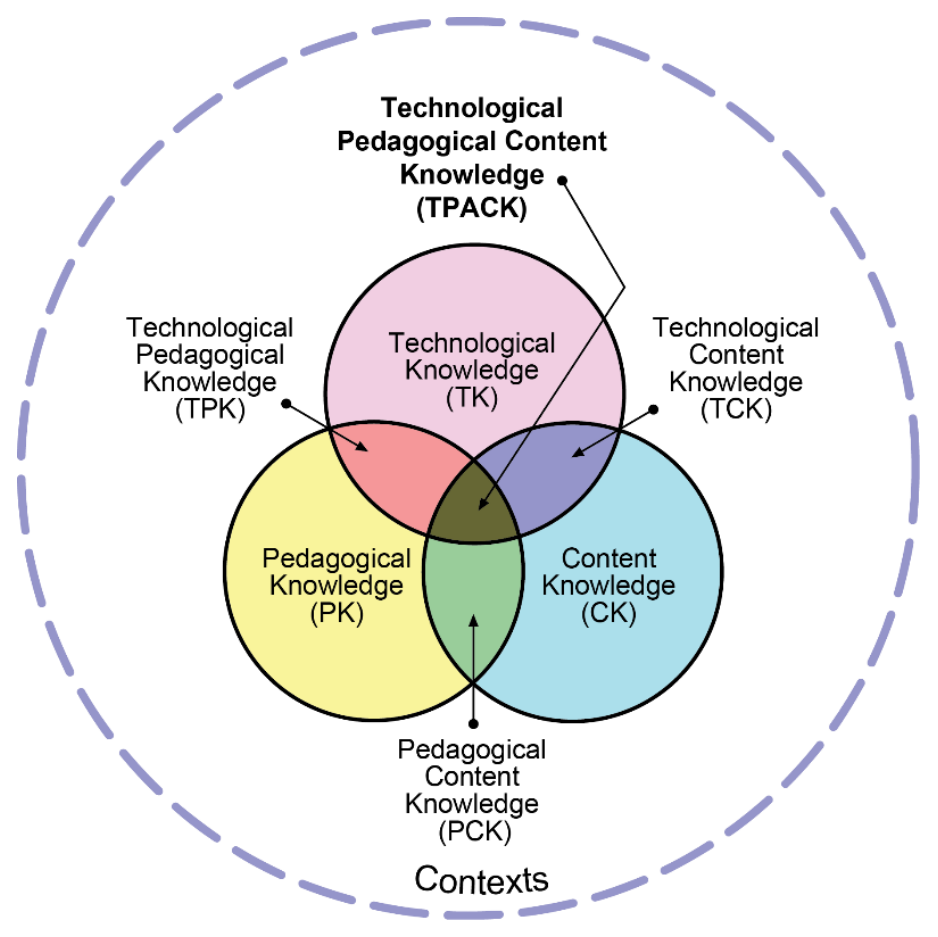

Source: http://www.tpack.org/

"Reproduced by permission of the publisher, (C) 2012 by tpack.org"

Journal of Teaching and Learning with Technology, Vol. 4, No. 1, June 2015.

jotlt.indiana.edu 


\section{Making it Work}

This project was successful because people with diverse skill sets worked together to develop a new approach to nurse practitioner distance education. Each team member came from a unique perspective that required a blending of expertise to develop a cohesive team. All of the team members differed in their educational background and approach to getting work done, and we spoke using a different lexicon.

To help the team coalesce, each member identified their area of expertise and what they would bring to this project. Being aware of the professional differences assisted us to see the value that each member contributed to the whole. There were difficulties along the way with ego and personalities but continually restating the purpose and reaffirming the importance of each member's contributions facilitated the over-arching goal being achieved. We all learned the language of each other's discipline so we could efficiently problem solve.

Once the team was in place the faculty member outlined the specific learning outcomes for this new experience. This required significant reflection for the faculty and a sharing of the advanced practice nurses' educational needs with the interprofessional team. Assisting the students in learning the foundational skill of diagnosing became the unifying principle by which every decision was made. Everything that was discussed by the team as a possible learning strategy had this as the endpoint.

The Instructional designer understood distance education and how to achieve learning outcomes using technology, a skill set in which the faculty member had less depth. The design process for the ICS involved using a storyboard to clearly depict how the ICS would move through a given case study. While the nursing faculty member was teaching the instructional designer about nursing, the instructional designer was teaching the nursing faculty about instructional design!

By employing the Backwards Design Model, we were able to move from learning outcomes backwards to instructional strategies (Wiggins \& McTighe, 1998). Additionally, by walking through the activity backwards, we determined the best places to insert questions, develop interactivity, assess knowledge, and fold in reflection. Once we completed this portion of the design phase we moved into developing the storyboard. The storyboard provides a physical layout of the plans for progression through the case (Smith \& Ragan, 2005).

Figure 2:

Example of the Storyboard
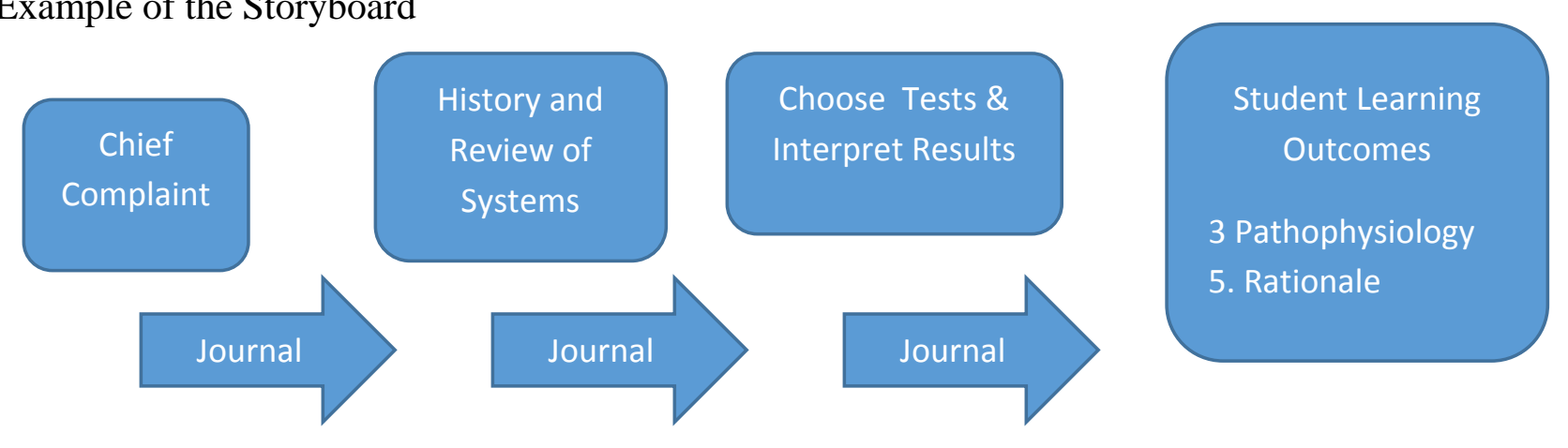

Journal of Teaching and Learning with Technology, Vol. 4, No. 1, June 2015. jotlt.indiana.edu 
The information technologist (IT) brought the knowledge of how to transform the ideas and strategies into reality. The IT partnered with the instructional designer to build the ICS. Additionally, the IT provided input on the best hardware and software applications and counseled us on how students would manage technological problems. He video-recorded our interactions with the standardized patients and edited the video-recordings. IT controlled sound and video quality, providing adequate lighting and re-filming when audio quality was marginal.

The completed ICS made it possible for distance learning students to engage in a virtual encounter with a standardized patient. ICS components included acquiring the focused health history, participating virtually in a physical assessment, reviewing lab data and diagnostic testing. This data gathering culminates in the student developing a list of differential diagnoses with a rationale. To involve multiple learning domains we asked the students to journal about their preparedness, anxieties, ability to develop appropriate questions, and overall confidence (Kolb, 1984).

\section{Future Implications}

After completing the rigorous design and development process we were eager to determine if our distance learning students using the ICS were able to achieve learning outcomes equivalent to those achieved by our on-site students interacting with standardized patients. We conducted a mixed method study that supported the conclusion that the ICS provided distance students with experiential learning with outcomes comparable to those achieved by on-site students (Colella \& Beery, 2014).

Working together from an abstract concept to reality was an exciting journey. Faculty need to maximize opportunities to solve educational dilemmas using an interprofessional team. Being aware of the needed steps minimizes confrontation, lack of focus and damage to collegial connections. Education is enhanced by the collaboration of experts, those with the subject matter, design, and technological expertise.

We believe that the Interactive Case Study format is flexible and could be useful to instructors from disciplines outside of healthcare. For example, a history professor could develop an ICS that would allow students to engage in a re-creation of an historical event or an English faculty member could help students engage with a text in an exciting and highly interactive way.

\section{References}

AACN (2014). Enrollment and Graduations in Baccalaureate and Grate Programs in Nursing. American Association of Colleges of Nursing: Washington, D.C.

Colella, C. \& Beery, T.A. (2014). Teaching Differential Diagnosis to Nurse Practitioner Students in a Distance Program. Journal of Nursing Education. 53(8). 433-438.

Koehler, M. J. \& Mishra, P. (2008). Introducing TPCK. Handbook of Technological Pedagogical Content Knowledge (TPCK) for educators (pp. 3-9). New York: Routledge.

Kolb, D. A. (1984). Experiential learning: Experience as the source of learning and development. Englewood Cliffs, NJ: Prentice Hall.

Journal of Teaching and Learning with Technology, Vol. 4, No. 1, June 2015.

jotlt.indiana.edu 
Colella, C., Rota, M., \& Beery, T.

Smith, P.L., \& Ragan, T.L. (2005). Instructional design: Third edition. Hoboken, NJ: John Wiley\& Sons, Inc.

Wiggins, G. P., \& McTighe, J. (1998). Understanding by Design. Alexandria, VA: Association for Supervision and Curriculum Development.

Journal of Teaching and Learning with Technology, Vol. 4, No. 1, June 2015.

jotlt.indiana.edu 